\title{
Mothers' Employment and Nutritional Status of Under-five Children Attending Selected Child Welfare Centre, Dhaka Cantonment
}

\author{
Chowdhury IAQ \\ DOI: https://doi.org/10.3329/jafmc.v16i1.53832
}

\section{Abstract}

Introduction: Nutritional status of children is one of the major predictors of child survivors and a proxy indicator for assessing the entire population health status. Despite the various efforts, malnutrition among children is remaining as a major public health problem in Bangladesh. Maternal employment status exerts strong influence over child nutrition status.

Aim: To find out the effect of maternal employment on nutritional status of 0-59 month-old children attending Malabika CWC at Dhaka Cantonment.

Methods: This cross sectional study was conducted at 'Malabika' Child Welfare Centre at Dhaka Cantonment from 01 March 2012 to 30 June 2012. A total of 110 children were selected conveniently. Data were collected from mothers by face to face interview and analyzed by SPSS 19. Association was assessed with Chi square test. The prevalence of malnutrition assessed by different indices of nutritional status based on Weight for Age Z-score, Height for Age Z-score and Weight for Height Z -Score following the WHO and NCHS guidelines and cut-off points.

Results: The prevalence of stunting, underweight and wasting was found to be $61.4 \%, 56.3 \%$ and $61.3 \%$ among the children of employed mother respectively. These all 3 prevalence are higher than the children of unemployed mothers. The association between nutritional status of under-five children of employed and non-employed mothers was found statistically significant $(p<0.05)$. Nutritional status of employed mothers 'children were found worsen than unemployed mothers' children.

Conclusion: This study provides an account of still high prevalence of malnutrition which trade-off between mothers' employment and children's nutritional status. Addressing factors like family size, duration of breast feeding, empowering women, monthly family income, mothers' education are key efforts to reduce child's malnutrition.

Key-words: Nutritional status, under five children, Wasting, Stunting, Underweight.

\section{Introduction}

Malnutrition is one of the catastrophes on human life affecting millions of lives worldwide. Developing countries are the worst affected. It has been recognized as one of the major causes of morbidity and mortality among the children less than five years. Adequate nutrition is essential in early childhood to ensure healthy growth, proper organ formation and function, a strong immune system and neurological and cognitive development. Economic growth and human development require well-nourished populations who can learn new skills, think critically and contribute to their communities ${ }^{1}$.

Severe acute malnutrition affects 4,50,000 children in Bangladesh every year while close to 2 million children have moderate acute malnutrition. Almost $41 \%$ of children under five years of age are stunted, $16 \%$ of children under five years of age are wasted, $36 \%$ of children under five years of age are underweight. Anaemia affects $52 \%$ of children under five years of age in Bangladesh. An estimated one third of deaths among children under age 5 are attributed to under nutrition².

Traditionally, a woman's place has been in her home and a generation ago, her employment outside her home was looked down by the society. This situation has now changed and women have started seeking employment outside their homes. These entering the work field have both negative and positive effects, the one is that it increases the family income and it may give the women some economic independence and status in the society. It, however also increases her work load and cuts into the time that she has to spend with her children as breast feeding, preparing food and seeking preventative and curative medical care are crucial for children's healthy development ${ }^{3}$. This inevitable change, women entering the work field have an effect on the child care and development. The net effects on children's well-being are likely to vary. Therefore, it is important to assess whether the nutritional status of children is affected by the mother's employment or not.

This study population of army is a selective group of people of the country who get better treatment facilities, living conditions, better education for the ailment of their children and that is why this study will enrich our knowledge about the prevalence of malnutrition among the under five children of employee and non-employee mother. 


\section{Materials and Methods}

This cross-sectional study was carried out among 110 conveniently and randomly selected children and their mothers as respondents attending Malabika CWC from 01 March 2012 to 30 June 2012. A total of 55 employed and 55 unemployed mothers were interviewed using a structured, pre-tested questionnaire. An electronic weighing scale to measure the weight, a standard height scale to measure the height were used. All data collected were analyzed by SPSS 19 to determine the mean, frequencies and their relationships. Association among the study parameters was assessed with Chi square and Pearson Chi square test. P value of less than 0.05 was taken as significant level with $95 \%$ confidence intervals. A predesigned and pretested structured questionnaire was used to record information on anthropometric measurements. The prevalence of malnutrition assessed by different indices of nutritional status based on Weight for Age Z-score (WAZ), Height for Age Z-score (HAZ) and Weight for Height Z-Score (WHZ). Anthropometry was done by standard scales and was compared with reference NCHS standard. Study was approved by Institutional Review Boards (IRB) at Armed Forces Medical Institute (AFMI) under Bangladesh Univeristy of Professionals (BUP). Informed consent was obtained from the study participants.

Table-I: Distribution of children by age and sex $(n=110)$

\begin{tabular}{|c|c|c|c|}
\hline \multirow{2}{*}{ Age (months) } & \multicolumn{2}{|c|}{ Sex } & \multirow{2}{*}{ Total } \\
\cline { 2 - 3 } & Male & Female & \\
\hline $\mathbf{0 1 - 2 4}$ & $10(15.1 \%)$ & $05(11.4 \%)$ & $15(13.6 \%)$ \\
\hline $\mathbf{2 5 - 3 6}$ & $21(31.9 \%)$ & $14(31.8 \%)$ & $35(31.8 \%)$ \\
\hline $\mathbf{3 7 - 4 8}$ & $25(37.8 \%)$ & $22(50.0 \%)$ & $47(42.7 \%)$ \\
\hline $\mathbf{4 8 - 6 0}$ & $10(15.1 \%)$ & $03(6.8 \%)$ & $13(11.9 \%)$ \\
\hline Total & $66(100.0 \%)$ & $44(100.0 \%)$ & $110(100 \%)$ \\
\hline
\end{tabular}

\section{Results}

Among male, the highest (37.8\%) age group was 37-48 months and among female, highest (50\%) age group was 37-48 months. Mean $( \pm S D)$ age of study population was $31.33 \pm 16$ months (Table-I). According to Weight for Age z-score, total underweight children were 32(29\%), according to Height for Age z-score total stunted children were $44(40.0 \%)$, according to Weight for Height z-score total wasted children were 26(23.6\%) (Table-II). The overall child malnutrition (stunting, underweight and wasting) was found much higher among children of 25-48 months age group which is $81.8 \%, 65.6 \%$ and $88.4 \%$ respectively. Similarly stunting, underweight and wasting were most common among children with mothers' education level up to SSC which was $72.7 \%, 81.2 \%$ and $80.8 \%$ respectively. Prevalence of stunting, underweight and wasting among male children were higher than that of female children which was $70.5 \%, 71.9 \%$ and $73.1 \%$ respectively (Table-III). The result of this study showed that the association of maternal employment with underweight and stunting were statistically significant $\left(x^{2}=.705\right.$ with $p=.041$ and $x^{2}=8.5$ with $\mathrm{p}=.003)$ (Table-IV).

Table-II: Distribution of children by Weight for Age (WAZ), Height for Age (HAZ), Weight for Height (WHZ) $(n=110)$

\begin{tabular}{|c|c|c|c|c|}
\hline Degree of Malnutrition & $\begin{array}{c}\text { Normal } \\
\text {-1SD to +2SD }\end{array}$ & $\begin{array}{c}\text { Mild } \\
\text {-2SD to -1SD }\end{array}$ & $\begin{array}{c}\text { Moderate } \\
\text {-3SD to -2SD }\end{array}$ & $\begin{array}{c}\text { Severe } \\
\text { <.3SD }\end{array}$ \\
\hline Weight for Age (WAZ) & $78(71 \%)$ & $10(9 \%)$ & $17(15 \%)$ & $05(4.5 \%)$ \\
\hline Height for Age (HAZ) & $66(60 \%)$ & $13(11.8 \%)$ & $22(20 \%)$ & $09(0.8 \%)$ \\
\hline Weight for Height(WHZ) & $84(76.3 \%)$ & $5(4.5 \%)$ & $12(10.9 \%)$ & $09(8.2 \%)$ \\
\hline
\end{tabular}

Table-III: Cross-classification of types of malnutrition by determinants factors

\begin{tabular}{|c|c|c|c|c|c|c|c|}
\hline \multirow{2}{*}{\begin{tabular}{c} 
Characteristics of Children \\
\cline { 2 - 7 }
\end{tabular}} & \multicolumn{2}{|c|}{ WAZ } & \multicolumn{2}{|c|}{ HAZ } & \multicolumn{2}{c|}{ WHZ } \\
\hline \multirow{3}{*}{$\begin{array}{c}\text { Age group of } \\
\text { Children in } \\
\text { months }\end{array}$} & $0-24$ & $07(21.8 \%)$ & $08(10.2 \%)$ & $05(11.3 \%)$ & $10(15.1 \%)$ & $02(7.6 \%)$ & $13(15.4 \%)$ \\
\cline { 2 - 7 } & $25-48$ & $21(65.6 \%)$ & $61(78.3 \%)$ & $36(81.8 \%)$ & $46(69.6 \%)$ & $23(88.4 \%)$ & $59(70.2 \%)$ \\
\cline { 2 - 8 } & $49-60$ & $04(12.5 \%)$ & $09(11.5 \%)$ & $03(6.81 \%)$ & $10(15.1 \%)$ & $01(3.8 \%)$ & $12(14.2 \%)$ \\
\cline { 2 - 8 } & Total & 32 & 78 & 44 & 66 & 26 & 84 \\
\hline \multirow{3}{*}{$\begin{array}{c}\text { Mother's } \\
\text { Education }\end{array}$} & Up to SSC & $26(81.2 \%)$ & $44(56.4 \%)$ & $32(72.7 \%)$ & $38(57.6 \%)$ & $21(80.8 \%)$ & $49(58.4 \%)$ \\
\cline { 2 - 8 } & HSC & $03(9.3 \%)$ & $10(12.8 \%)$ & $07(15.9 \%)$ & $06(9.1 \%)$ & $04(15.4 \%)$ & $09(10.8 \%)$ \\
\cline { 2 - 8 } & Graduation & $03(9.3 \%)$ & $24(30.8 \%)$ & $05(11.4 \%)$ & $22(33.4 \%)$ & $01(3.8 \%)$ & $26(30.9 \%)$ \\
\cline { 2 - 8 } & Total & 32 & 78 & 44 & 66 & 26 & 84 \\
\hline \multirow{3}{*}{ Sex } & Male & $23(71.9 \%)$ & $43(55.2 \%)$ & $31(70.5 \%)$ & $35(53.1 \%)$ & $19(73.1 \%)$ & $47(55.9 \%)$ \\
\cline { 2 - 8 } & Female & $09(28.2 \%)$ & $35(44.9 \%)$ & $13(29.5 \%)$ & $31(46.9 \%)$ & $07(26.9 \%)$ & $37(44.1 \%)$ \\
\cline { 2 - 7 } & Total & 32 & 78 & 44 & 66 & 26 & 84 \\
\hline
\end{tabular}

Table-IV: Nutritional status of the study children by maternal employment status ( $\mathrm{n}=110)$

\begin{tabular}{|c|c|c|c|c|c|}
\hline \multicolumn{2}{|c|}{ Variables } & Employed & Unemployed & Total & Test Statistics (with df=1) \\
\hline \multirow{2}{*}{ WAZ } & Underweight & $18(56.3 \%)$ & $14(43.7 \%)$ & $32(100 \%)$ & $\chi^{2}=.705$ \\
\cline { 2 - 6 } & Normal & $37(47.4 \%)$ & $41(52.6 \%)$ & $74(100 \%)$ & $\mathrm{p}=.041$ \\
\hline \multirow{2}{*}{ WHZ } & Wasted & $16(61.5 \%)$ & $10(39.5 \%)$ & $26(100 \%)$ & $\chi^{2}=1.81$ \\
\cline { 2 - 6 } & Normal & $39(46.4 \%)$ & $45(53.6 \%)$ & $84(100 \%)$ & $\mathrm{p}=.178$ \\
\hline \multirow{2}{*}{ HAZ } & Stunted & $27(61.4 \%)$ & $17(38.6 \%)$ & $44(100 \%)$ & $\chi^{2}=8.5$ \\
\cline { 2 - 6 } & Normal & $18(32.1 \%)$ & $38(67.9 \%)$ & $64(100 \%)$ & $\mathrm{p}=.003$ \\
\hline
\end{tabular}




\section{Discussion}

The objective of this study was guided by the study- hypothesized that, "children of employed mother likely to be well nourished compared to children of unemployed mother". The results of this study showed that childhood malnutrition persists and that maternal working status influenced their nutritional status through the interplay of wide ranges of significant factors. Most of the predictor was influencing stunting and underweight in a similar fashion. Educational attainment of mother, the biological factors such as sex of child were highly significant factors to describe the nutritional status. The mean age of the study children was $31.3 \pm 16$ months. Out of 110 children, $66(60 \%)$ were male and rest were female children and maximum children (male $37.8 \%$, female $50 \%$ ) are from 37-48 months age group. These study findings are in similar to the findings of another study conducted by Yazdini ${ }^{4}$ among the 2-5 years children of Armed Forces Personnel of Dhaka Cantonment.

It was evident from the present study, according to Z-scores total $29 \%$ of children were underweight, $40 \%$ were stunted and $23.7 \%$ were wasted. Stunting (40\%) was the commonest type of malnutrition followed by underweight and stunting. The study finding of the present study is dissimilar to the study finding conducted by Yazdani ${ }^{4}$ among children of 2-5 years of Armed Forces personnel in Dhaka Cantonment where $31.5 \%$ children were under weight, $13 \%$ were stunted and $18.5 \%$ were wasted. According to NIPORT (2016) $43 \%$ of children under five are stunted, $26 \%$ are wasted, and $36 \%$ are underweight (NIPORT, 2016) ${ }^{5}$. This difference with the current study is due to that, this study conducted couple of years back and by this time nutritional status of overall children has improved and moreover the children of Bangladesh Army enjoy a comparatively better economic and health care facilities.

Among the maternal related variables, the nutritional status of children (Stunting, underweight and wasting) was found to be influenced by mothers' educational level. Children with mothers' education level up to SSC are mostly malnourished. This finding is consistent with a study conducted by Rayhan et al ${ }^{6}(2006)$ which showed inverse relation of maternal education and child nutritional status. Mothers' education seemed to play a protective role against children malnutrition. Possible explanation could be educated mothers are more conscious about their children's health and they tend to look after their children in a better way ${ }^{6}$. In this study, we found that prevalence of stunting, underweight and wasting among male children was higher than that of female children which was $70.5 \%, 71.9 \%$ and $73.1 \%$ respectively.

The result of this study showed that the overall nutritional status of children of unemployed mothers is significantly better than that of children of employed mothers. It revealed that the risk of a child being stunted and underweight was higher among children of employed mothers $\left(x^{2}=8.5, p=.003\right.$ and $\left.x^{2}=.705, p=.041\right)$. This may be because of employed mothers may have less time available to supervise their children's activities and to prepare their meals. Most studies showed higher prevalence of childhood malnutrition among employed mothers compared to unemployed mothers. But this study result was supported by a study done by Araneo (2008) who revealed that full-time employment mothers had higher probability of the child being malnourished ${ }^{7}$. The findings of this research using multivariate approach will provide better insight about the likely predictors of malnutrition compared to multiple regression practices.

\section{Conclusion}

This study examined the influences of maternal employment status on children's nutritional status. The result of this study showed that the nutritional status of children significantly worsened with the employment status of mother of this cohort. It was identified that nutritional status also associated with age and sex of the children, maternal education, socio-economic status, birth order, improper weaning and feeding practices. The study concludes that improvement of feeding practices of preschool children, promotion and protection of optimal infant and child feeding practices, quality antenatal care, motivation and appropriate weaning school-based nutrition programs, a comprehensive nutrition program can reduce the malnutrition status.

\section{References}

1. UNICEF. Joint child malnutrition estimate, 2017. Available at https://data.unicef.org/topic/nutrition/malnutrition

2. WHO. Infant and young Child feeding; 2016. http://who.int/ mediacentre/factsheets/fs342/en/ (Accessed March 31st 2016).

3. Pandey A. Mother's status in the family and nutritional status of their under five Children, in rural West Bengal. Regional Leprosy Training and Research Institute, Lalpur, Raipur, 2006:1-8.

4. Yazdani MS. Nutritional Status and associated factors of two to five years children of Armed Forces Personnel living with parents in Dhaka Cantonment (Thesis), Dhaka 2007.

5. National Institute of Population Research and Training (NIPORT). Bangladesh Demographic and Health Survey, 2014. Dhaka, Bangladesh and Rockville, Maryland, USA: NIPORT, Mitra and Associates and ICF International.

6. Rayhan $\mathrm{MI}$ and Khan MSH. Factors causing malnutrition among under five children in Bangladesh. Pakistan J Nutr 2006; 5(6):558-62.

7. Araneo J. 2008. The effect of maternal employment on childhood obesity in the United States. Princeton University 2008:1-27. 